Article

\title{
Composition Optimization and Damping Performance Evaluation of Porous Asphalt Mixture Containing Recycled Crumb Rubber
}

\author{
Enmao Quan ${ }^{1,2, *}$, Hongke $\mathrm{Xu}{ }^{1, *}$ and Zhongyang Sun ${ }^{3}$ \\ 1 School of Electronics and Control Engineering, Chang'an University, Xi'an 710064, China \\ 2 Chongqing Water Resources and Electric Engineering College, Chongqing 402160, China \\ 3 China Merchants Chongqing Communications Technology Research \& Design Institute Co., Ltd., \\ Chongqing 400067, China; zhongyangsun999@126.com \\ * Correspondence: 2013032005@chd.edu.cn (E.Q.); xuhongke@chd.edu.cn (H.X.)
}

Citation: Quan, E.; Xu, H.; Sun, Z Composition Optimization and Damping Performance Evaluation of Porous Asphalt Mixture Containing Recycled Crumb Rubber. Sustainability 2022, 14, 2696. https:// doi.org/10.3390/su14052696

Academic Editor: Syed Minhaj Saleem Kazmi

Received: 11 February 2022 Accepted: 24 February 2022 Published: 25 February 2022

Publisher's Note: MDPI stays neutral with regard to jurisdictional claims in published maps and institutional affiliations.

Copyright: (c) 2022 by the authors. Licensee MDPI, Basel, Switzerland This article is an open access article distributed under the terms and conditions of the Creative Commons Attribution (CC BY) license (https:// creativecommons.org/licenses/by/ $4.0 /)$.

\begin{abstract}
Composition optimization of the asphalt mixture of pavement is one effective measures to reduce the harm of traffic noise. To improve the noise reduction effect of porous asphalt mixture (PAM) and promote the recycling of crumb rubber in highway engineering, the preparation parameters of high-viscosity modified asphalt for PAM were optimized in this study, and the mixture gradation was optimized based on the unbalance force and contact force of mixed aggregate. The effects of crumb rubber content and particle size on the damping performance and dynamic shear modulus of the mixture were studied. The effects of different preparation parameters on the performance of the PAM were comprehensively evaluated based on the orthogonal test, and preparation parameters of PAM were recommended. The results show that with the increase of crumb rubber content, the damping ratio of the mixed aggregate increases gradually. The addition of crumb rubber is conducive to improving the damping performance and toughness of the PAM, but it has an adverse impact on the bearing capacity. Under the condition of low strain, the damping ratio of the mixed aggregate containing $2-5 \mathrm{~mm}$ crumb rubber is $1.2-5$ times that of the mixed aggregate containing $0.6-1 \mathrm{~mm}$ crumb rubber. The recommended optimum content of crumb rubber in PAM is $4 \%$, and the optimum particle size of alternative aggregate is $2.36-4.75 \mathrm{~mm}$. The significant factors affecting Marshall stability are rubber particle content, asphalt aggregate ratio, mixing temperature, compaction times, and forming temperature. The rational utilization of crumb rubber in PAM is of positive significance to promoting the green development of highway construction and the harmless treatment of waste resources.
\end{abstract}

Keywords: porous asphalt mixture; noise reduction; rubber particle; composition optimization; damping performance

\section{Introduction}

Asphalt pavement is a type of pavement structure applied worldwide, and its construction technology has been relatively developed. Promotion of its service quality and sustainable development are hotspots in highway construction. With the continuous improvement of the economy and industrialization, scholars continue to improve the functionality of pavement, while ensuring its traffic capacity [1-3] so as to meet the functional requirements of the application environment for the pavement structure. The current functional asphalt pavements include noise-reducing pavement [4], permeable pavement [5,6], de-icing pavement [7], energy harvesting pavement [8-11], low heat-absorbing pavement [12], and degraded exhaust pavement [13]. At present, the functionality of asphalt pavement is mainly realized by optimizing pavement structure, adjusting mixture gradation, adding functional materials, and embedding functional devices [14-16]. Among different types 
of functional pavement, the porous asphalt mixture (PAM) is pavement with a macroporous structure formed by adjusting gradation, which has multiple functions such as noise reduction, skid resistance, and drainage. This pavement structure has been gradually popularized and applied in hot and rainy areas worldwide [17-19]. In addition, with the global promotion of the concept of sponge city construction, porous asphalt pavement (PAP) has gradually become an indispensable part of the construction planning of sponge cities. The collaborative work of permeable pavement and municipal drainage facilities is conducive to optimizing rainwater runoff control of sponge cities, improving the ability to address climate disasters, and weakening the heat island effect. Its construction and application promote the green development of urban construction $[20,21]$.

At present, there have been some studies on the road performance of PAM [6,18,22,23]. The bearing capacity of PAP mainly depends on the intercalation of large-size aggregate and the cementation of binder [24,25], and improving the adhesion of binder is a critical way to ensure its durability [26,27]. In addition, in terms of functional research on noise reduction of PAP, since the functionality of PAP is inseparable from its macroporous structure, scholars have mainly analyzed the effects of void structure characteristics, aggregate particle size, and layer thickness on the functionality of PAP [28-30]. Compared with dense-graded asphalt pavement, the service environment of PAP is worse. Especially in the rainy season, PAP is affected by load, high temperature, and dynamic water scouring at the same time [31-33]. With the structural damage of PAP, its functionality is also significantly attenuated, which affects driving safety. Considering road performance durability and functional durability is still the main technical problem faced by the studies of PAM.

One of the main reasons PAP is gradually being popularized and deeply studied is its unique noise reduction function compared with dense-graded asphalt pavement. At present, with the rapid advancement of global urbanization, traffic noise has become the largest source of noise in cities, which has a severe impact on the physical and mental health of urban residents [34]. Driving noise is closely related to road condition, driving speed, tire pattern, and other factors [35-37]. The noise generated by the interaction between tire and road accounts for $80-90 \%$ of driving noise. Pavement structure optimization is the most economical and environmental protection method to reduce urban noise pollution [27,38]. The connecting pores of PAP can promote the transformation of noise generated by the interaction between tire and pavement from sound energy to internal energy, so as to achieve the effect of noise reduction. At present, scholars have carried out relevant research on the sound absorption mechanism of PAP. Alber et al. [39] obtained the spatial parameters of the microstructure of porous asphalt mixture through CT scanning and discussed the relationship between pore geometry and acoustic characteristics. Sun et al. [28] took the sound absorption effect of asphalt mixture and the variation law of the noise attenuation curve under different frequencies as the evaluation index, and analyzed the influence of gradation type on the noise reduction effect of asphalt pavement. Wang et al. [40] compared the effects of gradation, porosity, thickness, and noise frequency on the sound absorption performance of pavement. They found that the addition of rubber particles was conducive to improving the noise reduction effect of pavement. The causes of traffic noise mainly include tire vibration noise, air pumping effect, and aerodynamic effect [38]. The main ways of reducing road noise include reducing damping vibration during driving and improving the sound absorptivity of the mixture [41]. Previous studies have tried to use crumb rubber in asphalt pavement structures to improve the damping and noise reduction of pavement and promote the resource utilization of waste tires [41-43]. Waste crumb rubber is an excellent damping material. Adding crumb rubber into asphalt mixture can promote the vibration intensity of the pavement structure during driving and optimize the surface texture characteristics of the pavement structure. The introduction of waste crumb rubber is of positive significance to improving pavement skid resistance and noise reduction characteristics. At present, there is little research on PAP containing crumb rubber, and the influence of different crumb rubber content and particle size on the damping performance and deformation characteristics of the mixture is not clear. Therefore, it is necessary to 
evaluate the effect of preparation parameters on the performance of PAM, so as to optimize the composition of PAM with crumb rubber and realize the synergistic enhancement of pavement structural performance and functionality.

In this study, the preparation process of high-viscosity modified asphalt was optimized, combined with the performance requirements of PAP. The mixture gradation was determined based on the aggregate extrusion force of different graded mixtures. The effects of rubber particle content and particle size on the damping performance and dynamic shear modulus of mixtures were analyzed with dynamic response tests. The effects of different parameters on the performance of the mixture were comprehensively evaluated based on the orthogonal test, and optimal preparation parameters of PAM were recommended. The purpose of this study is to optimize the composition design of PAM containing crumb rubber, promote the resource utilization of waste rubber particles in PAP, and improve the noise reduction performance and service durability of PAP.

\section{Materials and Methods}

\subsection{Materials}

The durability of PAP is mainly related to the embedded state and bonding state among aggregates. Compared with dense-graded asphalt mixture, PAP is more vulnerable to dynamic water scouring during service. Therefore, asphalt binder with excellent bonding performance is often used to prepare PSM. When preparing PAM, a self-made high-viscosity SBS-modified asphalt was used. For preparing high-viscosity modified asphalt, the base asphalt was Lanlian No. 70 asphalt. The technical indexes are shown in Table 1. The SBS modifier was linear SBS, produced from Baling Petrochemical Co., Ltd, Yueyang, China. The technical indexes are shown in Table 2. DY-AD asphalt tackifier was used to improve the viscosity of modified asphalt. The technical indexes are shown in Table 3 . The gradation design of the PAM was based on the OGFC-13 asphalt mixture. Basalt aggregate was selected as gravel, and limestone mineral powder was used for the PAM.

Table 1. Technical indexes of base asphalt.

\begin{tabular}{cc}
\hline Items & Technical Indexes \\
\hline Penetration, $25^{\circ} \mathrm{C}(0.1 \mathrm{~mm})$ & 65 \\
Softening point $\left({ }^{\circ} \mathrm{C}\right)$ & 48.5 \\
Dynamic viscosity $\left(60^{\circ} \mathrm{C}\right)(\mathrm{Pa} \cdot \mathrm{s})$ & 265 \\
Viscosity $\left(135^{\circ} \mathrm{C}\right)(\mathrm{Pa} \cdot \mathrm{s})$ & 0.75 \\
Ductility $\left(10^{\circ} \mathrm{C}, 5 \mathrm{~cm} / \mathrm{min}\right)(\mathrm{cm})$ & 24.1 \\
Wax content $(\%)$ & 1.5 \\
Flashpoint $(\%)$ & 310 \\
\hline
\end{tabular}

Table 2. Technical indexes of SBS modifier.

\begin{tabular}{cc}
\hline Items & Technical Indexes \\
\hline Styrene to butadiene ratio & $30 / 70$ \\
Oil filling rate $(\%)$ & 0 \\
Volatile matter $(\%)$ & 0.46 \\
Ash $(\%)$ & 0.12 \\
$300 \%$ constant tensile stress $(\mathrm{MPa})$ & 4.5 \\
Tensile strength $(\mathrm{MPa})$ & 19.5 \\
Elongation at break $(\%)$ & 864 \\
Breaking permanent deformation $(\%)$ & 21 \\
Shore hardness $(\mathrm{A})$ & 70 \\
Melt flow rate (g/10 min) & 1.3 \\
\hline
\end{tabular}


Table 3. Technical indexes of asphalt tackifier.

\begin{tabular}{cc}
\hline Items & Technical Indexes \\
\hline Active ingredient content & $\geq 98.5 \%$ \\
Relative density $\left(\mathrm{g} / \mathrm{cm}^{3}\right)$ & 1.05 \\
Heating reduction & $\leq 0.06 \%$ \\
Addition amount & $0.5-2.0 \%$ \\
\hline
\end{tabular}

When adding crumb rubber into PAM, it needs to be noted that the strength and stiffness of crumb rubber are quite different from that of aggregate. Therefore, adjusting the particle size and content of crumb rubber has a significant impact on the damping performance and road performance of the mixture. In this study, three types of crumb rubber with particle sizes of 2-5 mm, 1-3 mm, and 0.6-1 mm were selected to replace the gravel with a size of $2.36-4.75 \mathrm{~mm}, 1.18-2.36 \mathrm{~mm}$, and $0.6-1.18 \mathrm{~mm}$, respectively; the crumb rubber with different particle sizes is shown in Figure 1. The crumb rubber came from waste tires. The technical indexes are shown in Table 4. At present, the mixing methods of crumb rubber in asphalt mixture mainly include the equal volume substitution method and equal mass substitution method. The equal mass substitution method is suitable for the situation of small rubber particle size and small rubber content. To ensure that the gradation of PAM remains unchanged after adding crumb rubber, the equal volume substitution method was used to replace aggregates.
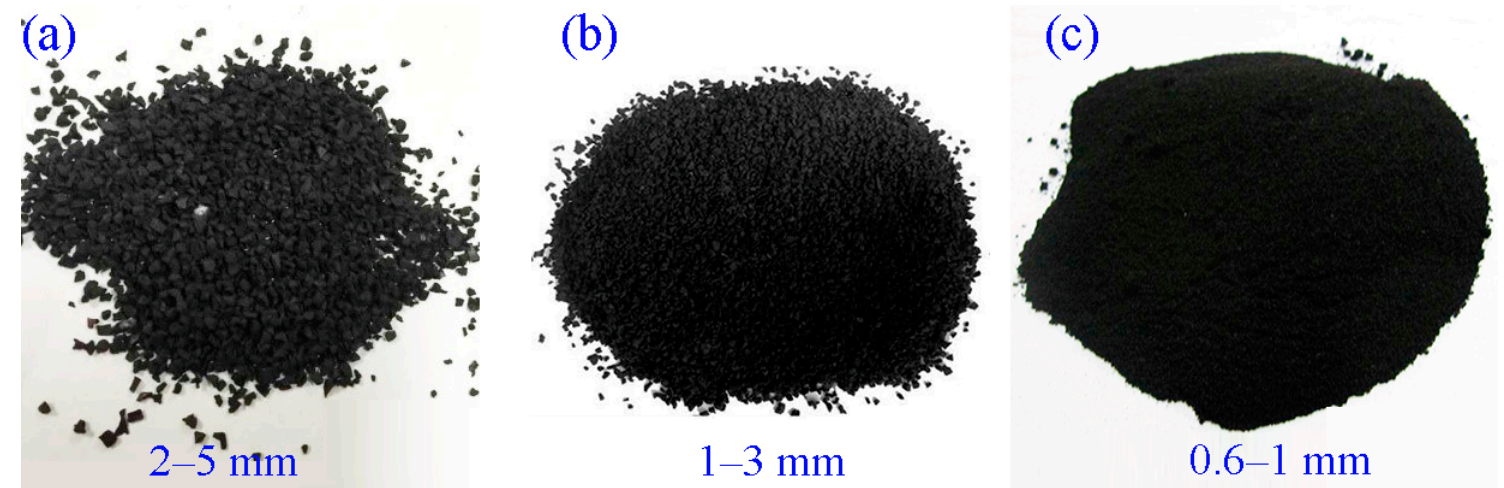

Figure 1. Crumb rubber with different particle sizes: (a) 2-5 mm; (b) 1-3 mm; (c) 0.6-1 mm.

Table 4. The technical indexes of crumb rubber.

\begin{tabular}{ccc}
\hline Items & Measured Value & Index Requirements \\
\hline Natural rubber content $(\%)$ & 48 & $\geq 30$ \\
Apparent density $\left(\mathrm{g} / \mathrm{cm}^{3}\right)$ & 1.05 & - \\
Shore hardness $(\mathrm{A})$ & 60 & $\geq 55$ \\
Content of elongated and flat & 9 & $\leq 10$ \\
particles $(\%)$ & 0.5 & - \\
Moisture content $(\%)$ & & \\
\hline
\end{tabular}

\subsection{Test Method}

\subsubsection{Preparation of High-Viscosity Modified Asphalt}

The influence of the preparation process on asphalt performance was mainly investigated when preparing high-viscosity modified asphalt. The preparation steps of high-viscosity modified asphalt were as follows. (1) The base asphalt was weighed and heated to $135^{\circ} \mathrm{C}$ for backup; SBS modifier and tackifier were weighed according to $4 \%$ and $1 \%$ of asphalt mass, respectively; and three groups of base asphalts were prepared at the same time. (2) The base asphalts were heated to $185^{\circ} \mathrm{C}$, SBS modifier and tackifier were added to the base asphalts according to the determined dosage, and the asphalts were sheared at low speed for $20 \mathrm{~min}$. (3) After low-speed shearing, the asphalt temperature was 
kept at $185^{\circ} \mathrm{C}$ and sheared at a rate of $5000 \mathrm{r} / \min$ for $1 \mathrm{~h}$. (4) The asphalt was mechanically mixed after completing high-speed shearing. For the three groups of modified asphalts, the mixing time was controlled to $2 \mathrm{~h}, 4 \mathrm{~h}$, and $6 \mathrm{~h}$, respectively. Asphalt temperature was maintained at $185-190{ }^{\circ} \mathrm{C}$ to swell the modifier fully, and the preparation of modified asphalt was completed. After preparation, the performance of high-viscosity asphalt was tested, including softening point, penetration $/ 25^{\circ} \mathrm{C}$, ductility $/ 15^{\circ} \mathrm{C}$, dynamic viscosity $/ 60^{\circ} \mathrm{C}$, adhesion $/ 25{ }^{\circ} \mathrm{C}$, and toughness $/ 25^{\circ} \mathrm{C}$, before and after the thin film oven test (TFOT) according to JTG E 20-2011 [44]. Five specimens were tested in each group, and the average of valid test results was reported.

\subsubsection{Primary Gradation Selection}

Firstly, the gradation of the OGFC-13 asphalt mixtures in different specifications was compared to analyze the grading characteristics. Table 5 shows the gradation requirements of OGFC-13 in various technical specifications. In different specifications, the aggregate of OGFC-13 with particle size between $4.75-9.5 \mathrm{~mm}$ accounts for the largest proportion. Therefore, when the gradation was preliminarily selected, the mass ratio of the aggregate with a size of $4.75-9.5 \mathrm{~mm}$ was adjusted, and three gradations were preliminarily determined. The grading curve is shown in Figure 2. The contact force state among aggregate particles under different grading was compared to optimize the gradation of PAM based on the discrete element method.

Table 5. Gradation requirements of OGFC-13 asphalt mixture in different technical specifications.

\begin{tabular}{ccccccccccc}
\hline \multirow{2}{*}{ Technical Specifications } & \multicolumn{8}{c}{ Mass Percentage Passing the Following Sieve Holes (mm) (\%) } \\
\cline { 2 - 24 } & $\mathbf{1 6}$ & $\mathbf{1 3 . 2}$ & $\mathbf{9 . 5}$ & $\mathbf{4 . 7 5}$ & $\mathbf{2 . 3 6}$ & $\mathbf{1 . 1 8}$ & $\mathbf{0 . 6}$ & $\mathbf{0 . 3}$ & $\mathbf{0 . 1 5}$ & $\mathbf{0 . 0 7 5}$ \\
\hline JTG D50-2017 [45] & 100 & $90-100$ & $60-80$ & $12-30$ & $10-22$ & $6-18$ & $4-15$ & $3-12$ & $3-8$ & $2-6$ \\
CJJ/T 190-2012 [46] & 100 & $90-100$ & $60-80$ & $12-30$ & $10-22$ & $6-18$ & $4-15$ & $3-12$ & $3-8$ & $2-6$ \\
JTG/T 3350-03-2020 [47] & 100 & $90-100$ & $40-71$ & $10-30$ & $9-20$ & $7-17$ & $6-14$ & $5-12$ & $4-9$ & $3-6$ \\
\hline
\end{tabular}

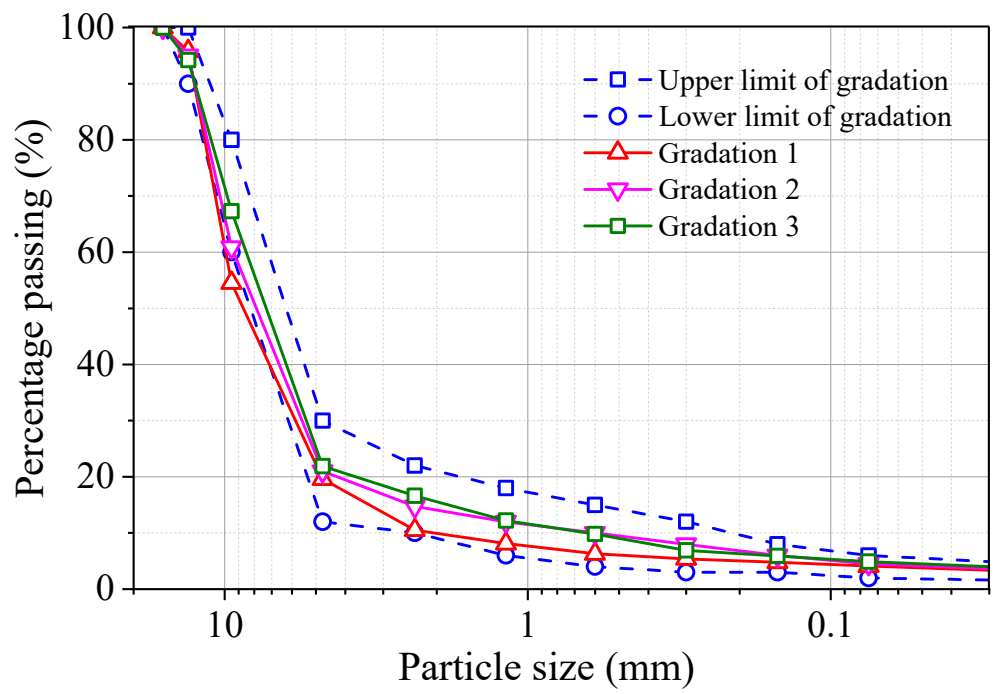

Figure 2. Primary grading curve of PAM with crumb rubber.

\subsubsection{Damping Performance Test}

The dynamic shear modulus and damping ratio of the mixed aggregate with crumb rubber were tested by dynamic response test. The influence of the addition of rubber particles on the damping performance of the mixed aggregate under different confining pressure was analyzed, and then the content and particle size of rubber particles were determined. The GZZ-50 resonant column instrument was used as the test instrument. The exciting axial force of the instrument is $10-100 \mathrm{~N}$, and the maximum lateral static pressure was 0.05-1.0 MPa. The damping performance of the mixed aggregate was tested 
by torsional shear vibration. Additionally, three parallel tests were conducted for each group. The damping performance of the material are characterized by the damping ratio and dynamic shear modulus. The test specimen size was $\Phi 50 \mathrm{~mm} \times 100 \mathrm{~mm}$, and the confining pressures were $100 \mathrm{kPa}, 200 \mathrm{kPa}$, and $300 \mathrm{kPa}$. The rubber particle content was $2 \%, 3 \%, 4 \%$, and $5 \%$, respectively.

\subsubsection{Optimization of Process Parameters of PAM with Crumb Rubber}

Compared with ordinary asphalt mixture, the mixing process and parameter optimization process of PAM is more complex. The optimized mixing parameters are conducive to avoiding the segregation of PAM with rubber particles and effectively ensure the cementation effect of binder and aggregate. When optimizing the mixing parameters, the main factors include asphalt aggregate ratio, crumb rubber content, aggregate heating temperature, feeding sequence, mixing temperature, mixing time of asphalt, mixing time of crumb rubber, compaction times, and forming temperature. To reasonably characterize the influence of different factors on the performance of PAM, the orthogonal table L32 $(4 * 9)$ was used to design the mixing process. Four levels were selected for each factor, and the best preparation process was determined by evaluating the influence of different influencing factors on the performance of PAM with crumb rubber. Three parallel tests were conducted for each condition. When optimizing the mixing process parameters of PAM with crumb rubber, the primary evaluation indexes included density, void volume (VV), void filled with asphalt (VFA), flow value (FV), and Marshall stability (MS). The test design scheme is shown in Table 6.

Table 6. The test design scheme.

\begin{tabular}{cccccc}
\hline Factors & Code & \multicolumn{4}{c}{ Levels } \\
\cline { 3 - 6 } & & $\mathbf{1}$ & $\mathbf{2}$ & $\mathbf{3}$ & $\mathbf{4}$ \\
\hline Asphalt aggregate ratio $(\%)$ & $\mathrm{A}$ & 6.0 & 5.5 & 5.0 & 4.5 \\
Crumb rubber content $(\%)$ & $\mathrm{B}$ & 4 & 3 & 2 & 1 \\
Aggregate heating temperature $\left({ }^{\circ} \mathrm{C}\right)$ & $\mathrm{C}$ & 195 & 185 & 175 & 165 \\
Mixing temperature $\left({ }^{\circ} \mathrm{C}\right)$ & $\mathrm{D}$ & 180 & 170 & 160 & 150 \\
Feeding sequence & $\mathrm{E}$ & $\mathrm{I}$ & $\mathrm{II}$ & $\mathrm{III}$ & $\mathrm{IV}$ \\
The mixing time after adding & $\mathrm{F}$ & 80 & 70 & 60 & 50 \\
asphalt $(\mathrm{s})$ & & & & & \\
The mixing time after adding crumb & $\mathrm{G}$ & 50 & 40 & 30 & 20 \\
rubber $(\mathrm{s})$ & $\mathrm{H}$ & 80 & 70 & 60 & 50 \\
Compaction times (times) & $\mathrm{I}$ & 170 & 160 & 150 & 140 \\
Forming temperature $\left({ }^{\circ} \mathrm{C}\right)$ & $\mathrm{Fum}$
\end{tabular}

Note: the material placing sequence I is: crumb rubber-aggregate-asphalt-mineral powder; the placing sequence II is: aggregate-hot crumb rubber-asphalt-mineral powder; the placing sequence III is: aggregate-cold crumb rubber-asphalt-mineral powder; and the placing sequence IV is: aggregate—asphalt—crumb rubber—mineral powder.

\section{Results and Discussion}

\subsection{Preparation Optimization of High-Viscosity Modified Asphalt}

Figure 3 shows the performance test results of high-viscosity modified asphalt prepared under different mixing processes. $S_{1}, S_{2}$, and $S_{3}$ represent the preparation conditions with stirring times of $2 \mathrm{~h}, 4 \mathrm{~h}$, and $6 \mathrm{~h}$, respectively. It can be found from Figure 3 that the mixing process has different effects on the properties of high-viscosity modified asphalt. The softening point of the modified asphalt under different mixing processes is greater than $85^{\circ} \mathrm{C}$, and its high-temperature performance is good. With the increase of mixing time, the softening point of the asphalt decreases gradually. The longer the mixing time, the more significant the decline of the softening point. Therefore, when taking the softening point as the evaluation index, it is recommended to control the mixing time to within $4 \mathrm{~h}$. In addition, the effect of mixing time on penetration, adhesion, and toughness of asphalt is similar. When the mixing time is $2-4 \mathrm{~h}$, the performances of high-viscosity modified 
asphalt changes little, and the test values increase with the continuous increase of mixing time. According to the ductility test results, the increase of mixing time is not conducive to the low-temperature performance of high-viscosity modified asphalt. The dynamic viscosity $/ 60^{\circ} \mathrm{C}$ of the asphalt increases significantly with the increase of mixing time and is greater than 20,000 Pa.s, which can meet the technical requirements of high-viscosity modified asphalt.
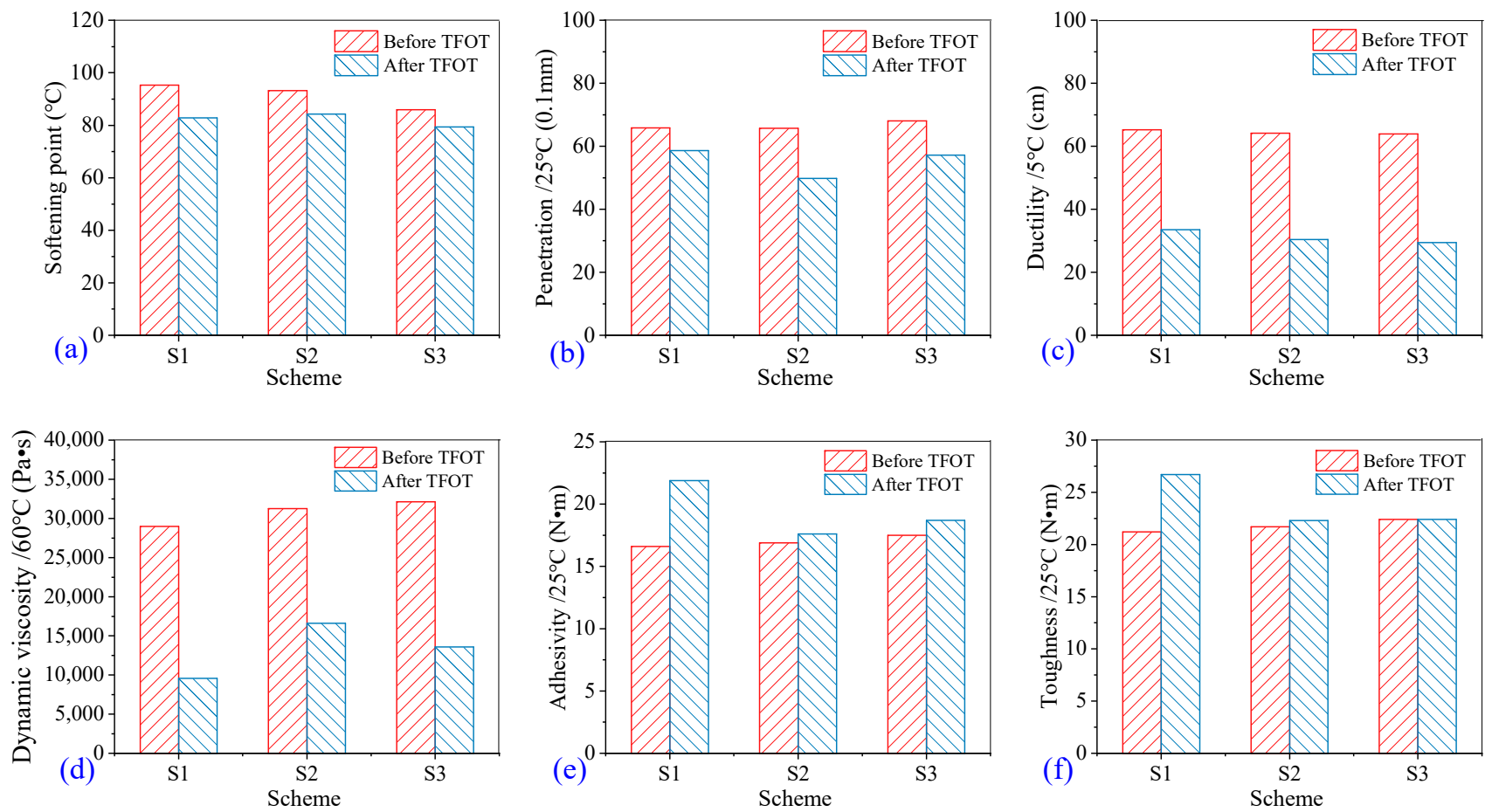

Figure 3. Performance test results of modified asphalt with different preparation processes: (a) softening point; (b) penetration $/ 2{ }^{\circ} \mathrm{C}$; (c) ductility $/ 5^{\circ} \mathrm{C}$; (d) dynamic viscosity $/ 60^{\circ} \mathrm{C}$; (e) adhesivity $/ 25^{\circ} \mathrm{C}$; (f) toughness $/ 25^{\circ} \mathrm{C}$.

The performance of high-viscosity modified asphalt after TFOT was further compared. As shown in Figure 3, the high- and low-temperature performance of highviscosity modified asphalt after TFOT was decreased; the high-temperature performance decreased slightly, while the low-temperature performance decreased significantly. The ductility $/ 15^{\circ} \mathrm{C}$ and dynamic viscosity $/ 60^{\circ} \mathrm{C}$ were reduced by about $50 \%$. It is worth noting that the toughness and adhesion of asphalt improved after TFOT, which may be related to the aging of matrix asphalt in high-viscosity modified asphalt [48]. When evaluating the performance of high viscosity modified asphalt, the main technical indexes include softening point, penetration, ductility, dynamic viscosity $/ 60^{\circ} \mathrm{C}$, adhesion, and toughness [46]. The technical requirements of high-viscosity modified asphalt are shown in Table 7. The technical indexes of SBS modified asphalt prepared under different mixing process conditions meet the specification requirements. Considering that the increase of mixing time does not significantly improve the technical performance of high viscosity modified asphalt, the preparation process of high-viscosity modified asphalt was finally determined as follows: high-speed shear for $1 \mathrm{~h}$, mechanical mixing for $2 \mathrm{~h}$, and preparation temperature controlled between $185-190^{\circ} \mathrm{C}$. 
Table 7. Technical indexes of high-viscosity modified asphalt for PAM with crumb rubber.

\begin{tabular}{cc}
\hline Items & Technical Standard \\
\hline Softening point $/\left({ }^{\circ} \mathrm{C}\right)$ & $\geq 80$ \\
Penetration $/ 25^{\circ} \mathrm{C}(0.1 \mathrm{~mm})$ & 40 \\
Ductility $/ 5^{\circ} \mathrm{C}(\mathrm{cm})$ & 30 \\
Dynamic viscosity $/ 60^{\circ} \mathrm{C}(\mathrm{Pa} \cdot \mathrm{s})$ & $\geq 2 \times 10^{4}$ \\
Adhesion $/ 25^{\circ} \mathrm{C}(\mathrm{N} \cdot \mathrm{m})$ & $\geq 15$ \\
Toughness $/ 25^{\circ} \mathrm{C}(\mathrm{N} \cdot \mathrm{m})$ & $\geq 20$ \\
\hline
\end{tabular}

\subsection{Gradation Optimization of PAM}

Replacing part of the aggregate of PAM with crumb rubber is conducive to giving play to the damping characteristics of rubber materials and giving the PAM the function of vibration and noise reduction [38,43]. To fully play the damping characteristics of crumb rubber particles, the mineral aggregate gradation should have good stability and make the internal stress distribution of the aggregate uniform under load. The three groups of primary gradation were simulated by the discrete element method, and the stability of mineral aggregate skeleton with different gradations was analyzed.

\subsubsection{Establishment of Grading Model Based on Discrete Element Method}

When the discrete element method was used to simulate the aggregate contact mode of PAM, the particle sliding connection model was adopted. The technical parameters are shown in Table 8. The model size of samples is $\Phi 200 \mathrm{~mm} \times 300 \mathrm{~mm}$. Based on the three groups of primary grading given in Figure 2, according to the mass percentage and density of each grade of aggregate, the number of particles of each grade of aggregate was calculated by using the self-contained command of discrete element software to form three grading models. For PAM, the intercalation among aggregates is mainly large particles. At the same time, considering that the increase of the number of small particles affects the calculation efficiency of the model seriously, the minimum particle size was $1.18 \mathrm{~mm}$ when the grading model was established. The particles number of PAM contained aggregates with different particle sizes are shown in Table 9.

Table 8. Technical parameters of discrete element model of PAM.

\begin{tabular}{cccc}
\hline Material & Density $\left(\mathbf{k g} / \mathbf{m}^{3}\right)$ & $\begin{array}{c}\text { Normal Stiffness of } \\
\text { Particles }(\mathbf{P a} / \mathbf{m})\end{array}$ & $\begin{array}{c}\text { Tangential Stiffness } \\
\text { of Particles (Pa/m) }\end{array}$ \\
\hline Aggregate & 2800 & $1 \times 10^{8}$ & $1 \times 10^{8}$ \\
\hline
\end{tabular}

Table 9. Particle number of PAM-containing aggregates with different particle sizes.

\begin{tabular}{|c|c|c|c|c|c|c|}
\hline \multirow{2}{*}{$\begin{array}{l}\text { Particle Size } \\
\text { Range (mm) }\end{array}$} & \multicolumn{2}{|c|}{ Gradation 1} & \multicolumn{2}{|c|}{ Gradation 2} & \multicolumn{2}{|c|}{ Gradation 3} \\
\hline & Proportion (\%) & $\begin{array}{c}\text { Number of } \\
\text { Particles }\end{array}$ & Proportion (\%) & $\begin{array}{c}\text { Number of } \\
\text { Particles }\end{array}$ & Proportion (\%) & $\begin{array}{c}\text { Number of } \\
\text { Particles }\end{array}$ \\
\hline $13.2-16$ & 4.20 & 16 & 5 & 19 & 5.8 & 22 \\
\hline $9.5-13.2$ & 41.30 & 140 & 34.1 & 116 & 26.9 & 91 \\
\hline $4.75-9.5$ & 34.90 & 392 & 39.9 & 448 & 45.4 & 510 \\
\hline $2.36-4.75$ & 9.10 & 248 & 6.3 & 172 & 5.3 & 144 \\
\hline $1.18-2.36$ & 2.40 & 548 & 2.7 & 617 & 4.4 & 1005 \\
\hline$<1.18$ & 1.80 & 2460 & 2 & 2733 & 2.4 & 3280 \\
\hline
\end{tabular}

\subsubsection{Stability Analysis of Mineral Aggregate Skeleton with Different Gradation}

The contact force characteristics of three groups of OGFC-13 were established using the discrete element program. The results show that the distribution state of contact force of different gradations is different, and there is obvious stress concentration in the skeleton structure of Gradation 1 and Gradation 3. The size and distribution of the contact force of 
Gradation 2 are relatively uniform, indicating that the stability of the grading skeleton is relatively good. To ensure the solution stability of the grading model, the changes of the mean unbalance force and mean contact force of different models were evaluated based on the calculation process. The changes of the mean unbalance force and mean contact force of the three grading models are shown in Figures 4 and 5. It can be seen from Figure 4 that the contact unbalance force of Gradation 2 decreases rapidly at the initial stage of the calculation, while the unbalance force of Gradation 1 and Gradation 3 stay at a high level after calculation for a period of time. According to Figure 5, the contact force distribution of Gradation 2 is more stable and has good skeleton stability in the calculation process. Therefore, it is recommended to design the composition of PAM with crumb rubber based on Gradation 2. This is conducive to giving full play to the damping effect of the mixture after using crumb rubber to replace part of the aggregate based on Gradation 2.
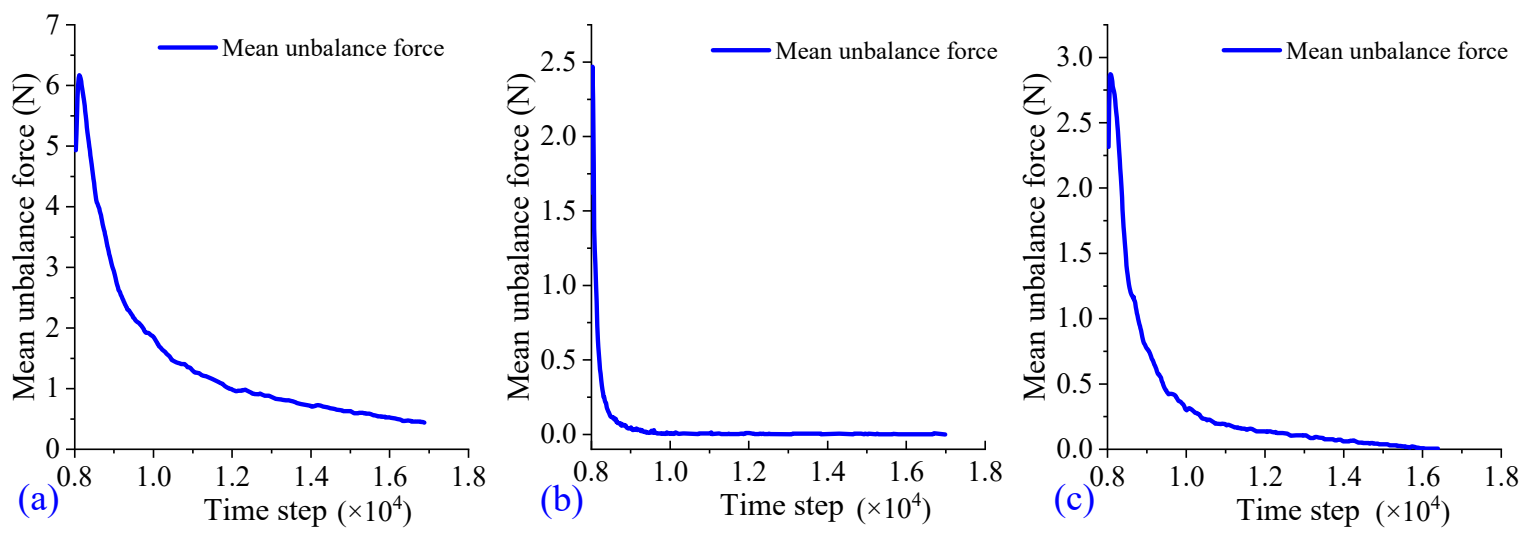

Figure 4. Distribution diagram of mean unbalance force: (a) Gradation 1; (b) Gradation 2; (c) Gradation 3.
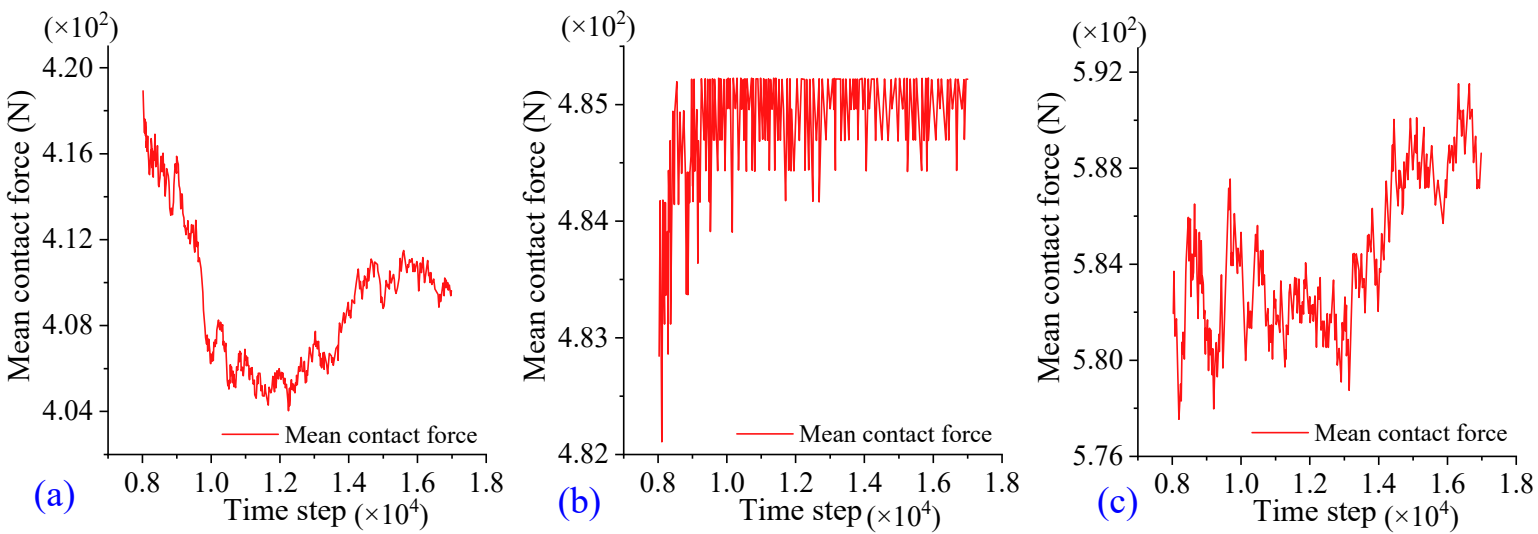

Figure 5. Distribution of mean contact force: (a) Gradation 1; (b) Gradation 2; (c) Gradation 3.

\subsection{Influence of Rubber Particle Distribution on Damping Performance}

3.3.1. Influence of Rubber Particle Content on Damping Performance

To analyze the influence of rubber particle content on the damping performance of mixed aggregate, crumb rubber with particle size specification of $2-5 \mathrm{~mm}$ was used to replace the aggregate with equal volume in the corresponding particle size range in the gradation of PAM. The replacement amounts are $2 \%, 3 \%, 4 \%$, and $5 \%$, respectively. The dynamic shear modulus and the damping ratio of the mixed aggregate under different confining pressures were tested. Figure 6 shows the loading failure process of the mixed aggregate samples mixed with crumb rubber. Figure 7 shows the variation of damping ratio of mixed aggregate samples with shear strain under different rubber substitution rates. 


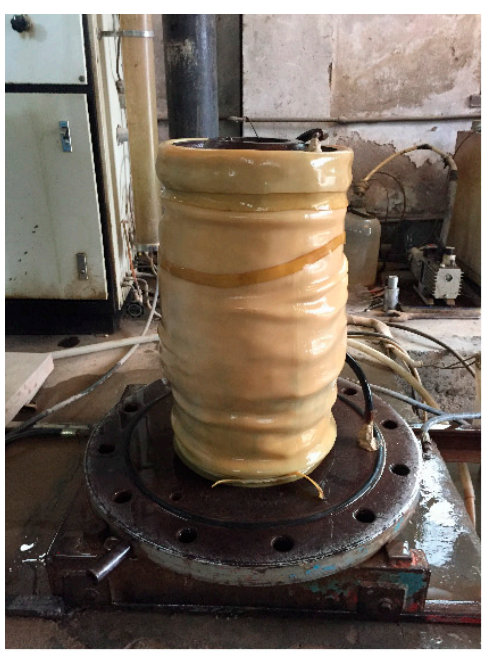

(a)

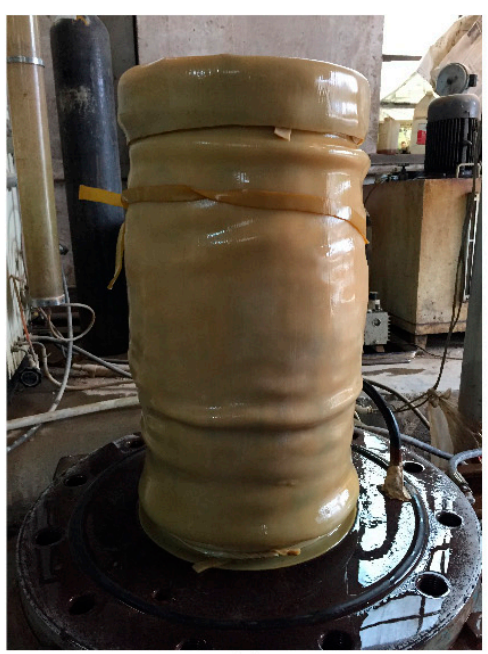

(b)

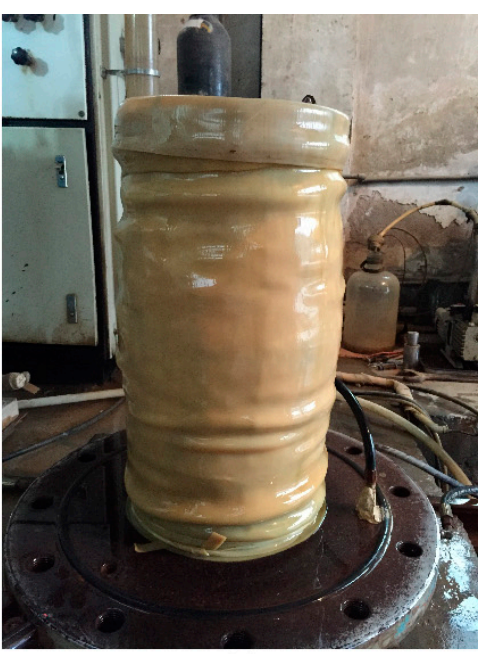

(c)

Figure 6. Samples after loading: (a) confining pressure $100 \mathrm{kPa}$; (b) confining pressure $200 \mathrm{kPa}$; (c) confining pressure $300 \mathrm{kPa}$.

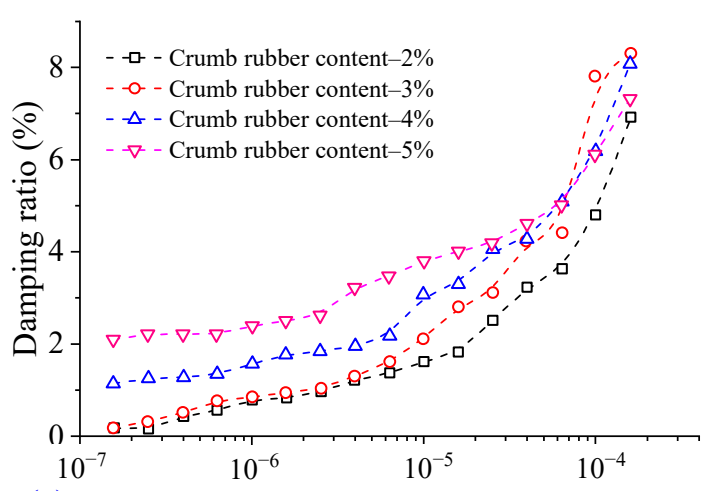

(a)

$$
\text { Shear strain }
$$

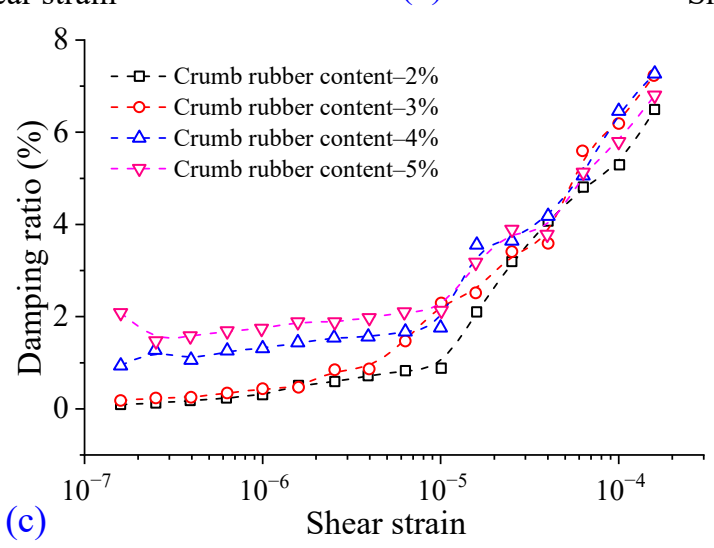

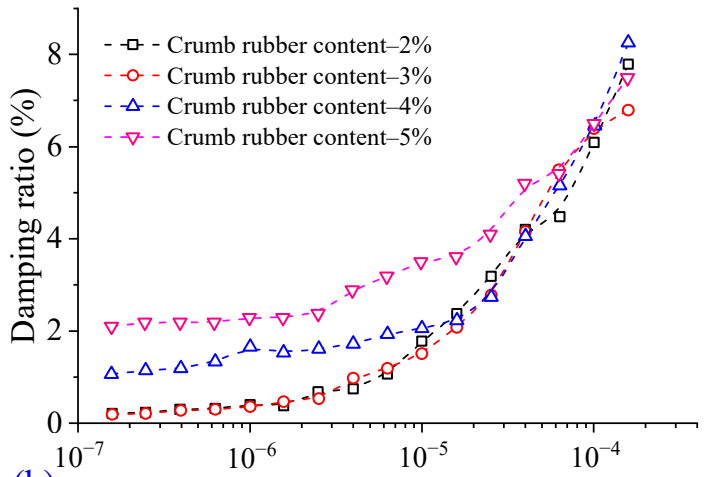

Shear strain

Figure 7. Variation of damping ratio of samples under different crumb rubber content: (a) confining pressure $100 \mathrm{kPa}$; (b) confining pressure $200 \mathrm{kPa}$; (c) confining pressure $300 \mathrm{kPa}$.

As shown in Figure 7, the damping ratio of mixed aggregate under different confining pressures increases with crumb rubber content. When the crumb rubber content is $5 \%$, the damping ratio of mixed aggregate under low strain conditions is more than $2 \%$, significantly higher than that of mixed aggregate with the crumb rubber content of $2 \%$. This indicates that the addition of crumb rubber is conducive to significantly improving the damping performance of the mixture. In addition, the variation trend of the damping ratio is related to the confining pressure. When the shear strain is less than $10^{-6}$, the variation range of the damping ratio of the mixed aggregate under different dosages is small, while the damping 
ratio of the mixed aggregate shows an increasing trend when the shear strain increases to a particular value under high confining pressure. When the shear strain is less than $10^{-5}$, the change of the damping ratio of the mixed aggregate shows an upward trend, which is mainly due to the introduction of rubber particles in the deformation process of the mixed aggregate, allowing the mixed aggregate to adapt to large deformation and realize the effective dissipation of energy. When the content of rubber particles is small, the energy dissipation is limited and the damping is small. When the shear strain is greater than $10^{-5}$, the variation trend lines of the damping ratio of samples with different rubber content with shear strain are staggered. The reason for this is that when the shear strain is significant, the specimen may be damaged, the relative displacement of aggregate and rubber particles is large, and the energy dissipation of the mixed aggregate gradually increases in the process of sample crack development. According to the variation law of damping ratio of mixed aggregate with shear strain under different confining pressures, when the shear strain is significant, the damping ratio of mixed aggregate with $4 \%$ crumb rubber is the greatest. To sum up, the introduction of rubber particles is conducive to improving the damping ratio of mixed aggregate. Therefore, rubber particles can be used to replace aggregate to increase the damping of the mixture and realize the damping and noise reduction effect of PAM.

The variation of the dynamic shear modulus of mixed aggregate samples under different rubber content is shown in Figure 8. With the increase of crumb rubber content, the dynamic shear modulus of the mixed aggregate gradually decreases. This indicates that the addition of crumb rubber is conducive to improving the toughness of the mixture, rather than ensuring its stiffness. Therefore, determining the appropriate crumb rubber content is conducive to ensuring the bearing capacity of the mixture. It can be seen from Figure 8 that the dynamic shear modulus of the mixture decreases greatly with the increase of shear strain at a low content of crumb rubber, while the attenuation trend of dynamic shear modulus decreases significantly when the crumb rubber content is $4 \%$, which indicates that the mixture samples with low crumb rubber content are damaged with the continuation of shear action, hence its relatively low deformation resistance. Although increasing the crumb rubber content is not conducive to ensuring the bearing capacity of the mixture, it is conducive to enhancing its deformation capacity and realizing the effectual dissipation of energy and the improvement of durability based on meeting the bearing capacity requirements. In addition, when the crumb rubber content increases from $2 \%$ to $5 \%$, the reduction rate of the dynamic shear modulus of mixed aggregate gradually increases. Especially when the crumb rubber content is more than $4 \%$, the dynamic shear modulus of the mixture clearly decreases under high confining pressure, which indicates that the increase of the crumb rubber content weakens the skeleton impaction of the mixture. In conclusion, the excessive addition of crumb rubber particles reduces the bearing capacity of the mixture significantly. When the dynamic shear modulus is selected as the evaluation index, the crumb rubber content should not exceed $5 \%$.

\subsubsection{Influence of Rubber Particle Size on Damping Performance}

Three kinds of crumb rubber with particle size specifications of 2-5 mm, 1-3 mm, and 0.6-1 $\mathrm{mm}$ were used to replace the aggregates with the corresponding particle size range; the replacement amount was $4 \%$. The dynamic shear modulus and the damping ratio under different confining pressures were respectively to analyze the influence of rubber particle size on the damping performance of mixed aggregates. The test results of the damping ratio of aggregates mixed with rubber particles of different specifications are shown in Figure 9. When the crumb rubber content is controlled to $4 \%$, the damping ratio of mixed aggregate increases gradually with the increase of rubber particle size, which shows that the rubber particle size also affects the damping characteristics of mixed aggregate. When $0.6-1 \mathrm{~mm}$ rubber particles are used to replace the aggregate in the mixture by equal volume method, the damping ratio is relatively small; that is, replacing this group of aggregate with crumb rubber has little impact on the damping effect of the mixture. Under the condition of low strain, the damping ratio of mixed aggregate with $2-5 \mathrm{~mm}$ rubber particle is $1.2-5$ times 
that of mixed aggregate with $0.6-1 \mathrm{~mm}$ rubber particle. The main reason for this is that the large particles play the role of the skeleton in the mixed aggregate. When the rubber particle size is large, the mixture can absorb more energy under the action of load. Under the high strain condition, the damping ratio of the mixed aggregate containing crumb rubber with different particle sizes tends to be the same, which is mainly due to the damage of the sample under the condition of large deformation, so the influence of rubber particle size on the damping effect of the mixture is gradually weakened. According to the grading curve of the mixture, the aggregate within the range of $2.36-4.75 \mathrm{~mm}$ accounts for the largest proportion in the selected gradations, and the total content of crumb rubber required for equal volume replacement of this group of aggregate is large. This shows that the selection of rubber particle size should be consistent with the main particle size of the particles in the aggregate gradation to achieve better damping performance.

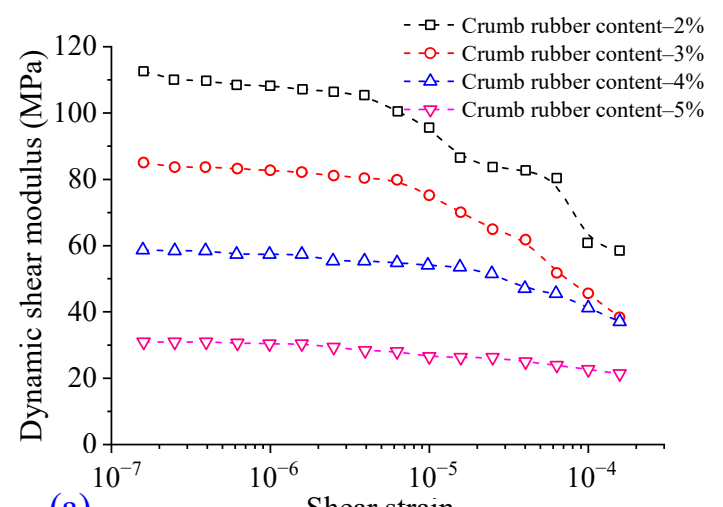

(a)

Shear strain

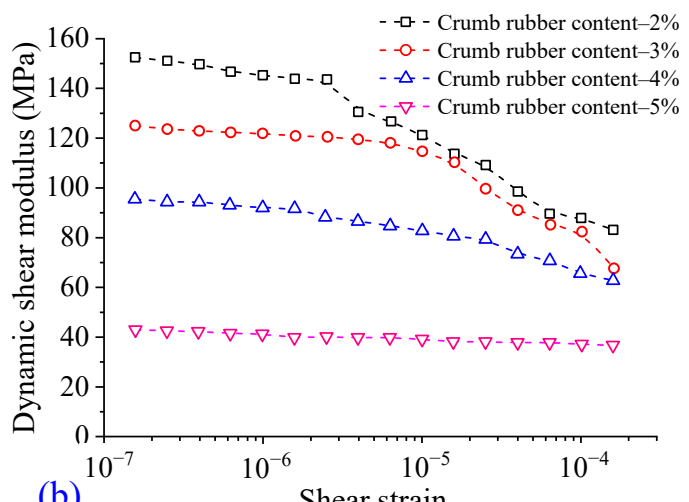

(b)

Shear strain

- - - Crumb rubber content $-2 \%$

- - - - Crumb rubber content-3\%

$-\triangle$ - Crumb rubber content- $4 \%$

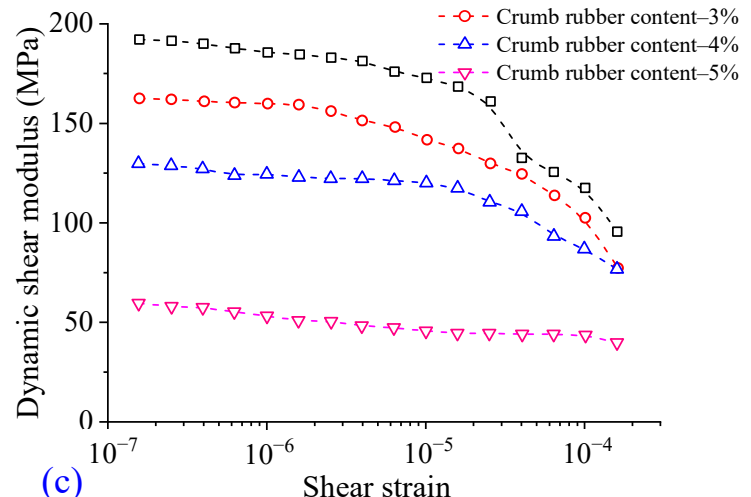

(c)

Shear strain

Figure 8. Variation of dynamic shear modulus of samples with different crumb rubber content: (a) confining pressure $100 \mathrm{kPa}$; (b) confining pressure $200 \mathrm{kPa}$; (c) confining pressure $300 \mathrm{kPa}$.

The test results of the dynamic shear modulus of samples with different rubber particle specifications are shown in Figure 10. When the crumb rubber content is $4 \%$, the dynamic shear modulus of mixed aggregate decreases gradually with the increase of rubber particle size. Under the low strain condition, the dynamic shear modulus of the mixture containing 2-5 mm crumb rubber is between $60-160 \mathrm{MPa}$, and the dynamic shear modulus of the mixture containing $0.6-1 \mathrm{~mm}$ crumb rubber is between $80-220 \mathrm{MPa}$. The rubber particle size significantly impacts the dynamic shear modulus of the mixed aggregate. When the shear strain increases to more than $10^{-5}$, the dynamic shear modulus clearly decreases with the increase of shear strain. When the shear strain is minor, the mixed aggregate is close to the elastic state, and the propagation energy loss of dynamic load stress wave in the mixed aggregate is slight. With the increase of shear strain, the relative displacement among particles of the mixture increases and gradually creates unrecoverable deformation; then, the dynamic shear modulus decreases rapidly. Based on the test results of damping ratio and dynamic shear modulus of the mixture containing crumb rubber, it is suggested 
that the optimal content of crumb rubber in the gradation of PAM is $4 \%$, and the particle size of alternative aggregate is $2.36-4.75 \mathrm{~mm}$.

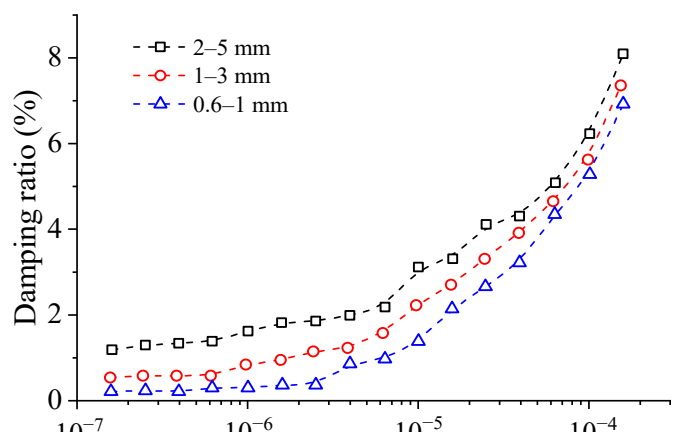

(a)

Shear strain

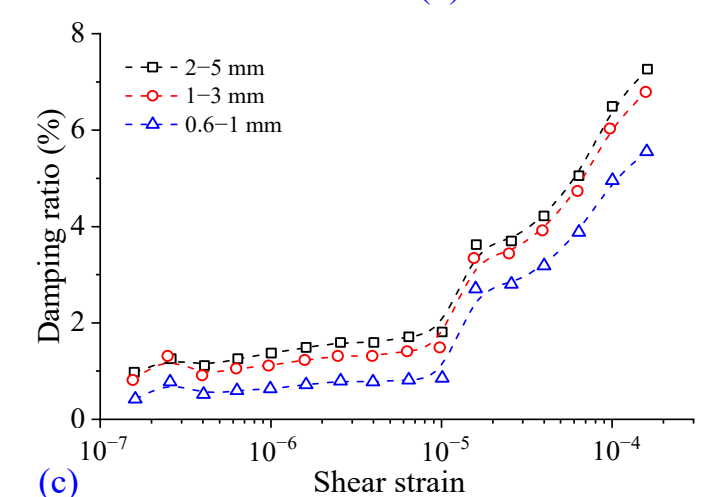

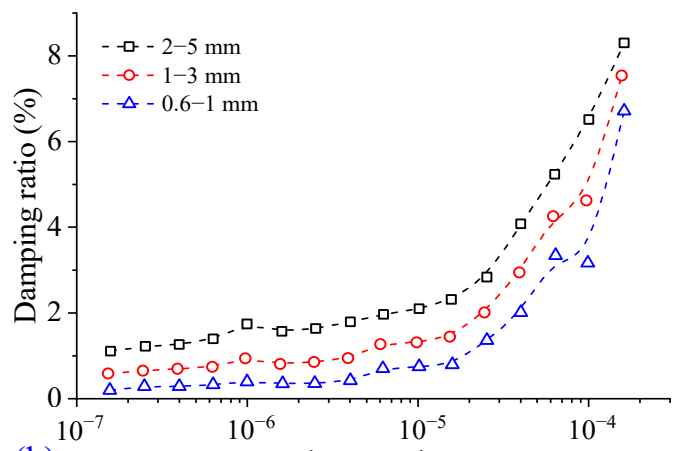

Shear strain

Figure 9. Variation of damping ratio of samples with different crumb rubber particle size: (a) confining pressure $100 \mathrm{kPa}$; (b) confining pressure $200 \mathrm{kPa}$; (c) confining pressure $300 \mathrm{kPa}$.

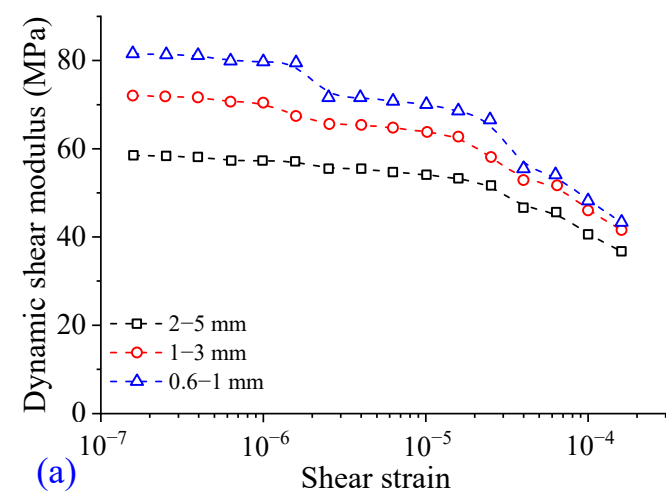

(a)

Shear strain

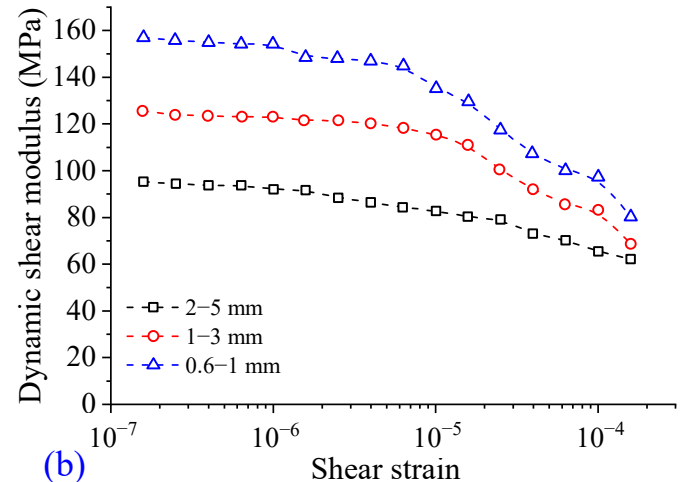

(b)

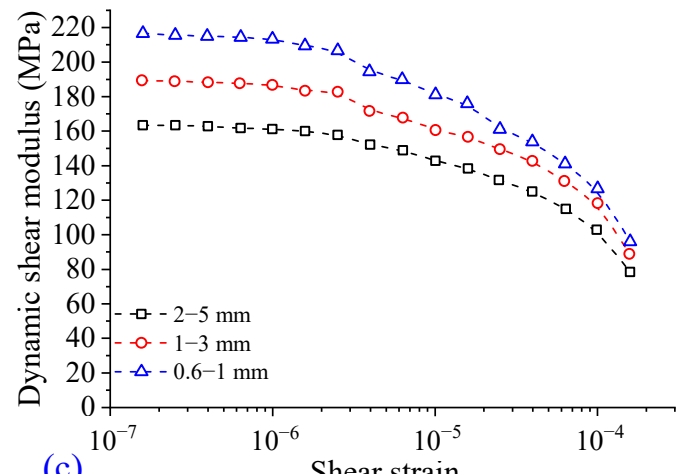

Figure 10. Variation of dynamic shear modulus of samples with different crumb rubber specifications: (a) confining pressure $100 \mathrm{kPa}$; (b) confining pressure $200 \mathrm{kPa}$; (c) confining pressure $300 \mathrm{kPa}$. 


\subsection{Performance Evaluation of PAM Containing Crumb Rubber}

\subsubsection{Analysis of Test Results}

Taking the density, VV, VFA, FV, and MS of Marshall specimens as evaluation indexes, the performance of Marshall specimens prepared under different factors was analyzed by range analysis and variance analysis to determine the influence of different factors on the performance of PAM. Figures 11-15 show the range analysis results of different properties. The influence degree of various factors on density, VV, VFA, FV, and MS can be determined based on the range analysis. The corresponding technical parameters can be adjusted according to the engineering requirements in actual engineering. The change of asphalt aggregate ratio (Factor A) has the most significant effect on the VFA and VV of the mixture, has a substantial impact on the density and MS, and has a weak influence on the FV of the mixture. The change of rubber particle content (Factor B) has a significant impact on the density, FV, and MS of the mixture, as well as on the VFA and VV. The increase of heating temperature (Factor C) has an impact on the VFA, VV, density, and MS of the mixture, but the impact degree is weak, and the impact degree on the FV is only higher than the asphalt aggregate ratio. The mixing temperature (Factor D) has a significant impact on the FV and MS of the mixture, but its impact is lower than factors $\mathrm{A}, \mathrm{B}$, and $\mathrm{H}$, and it has a weak effect on the other three indicators. The influence of material feeding sequence (Factor $E$ ) on the $\mathrm{VV}$ and density of the mixture is second only to factors $\mathrm{A}$ and $\mathrm{B}$, and its influence on FV, MS, and VFA is not apparent. The influence of mixing time after adding asphalt (Factor F) on VFA is second only to factors A and B, and it has a certain influence on VFA, $\mathrm{VV}$, and density. The mixing time after adding crumb rubber (Factor G) impacts the FV of the mixture and has a weak impact on other indicators. The impact of compaction times (Factor $\mathrm{H}$ ) on the FV is second only to factor $\mathrm{B}$, and has a weak effect on other indicators. When the forming temperature (Factor I) of the specimen is selected, the influence of the change of forming temperature on each index is not apparent.

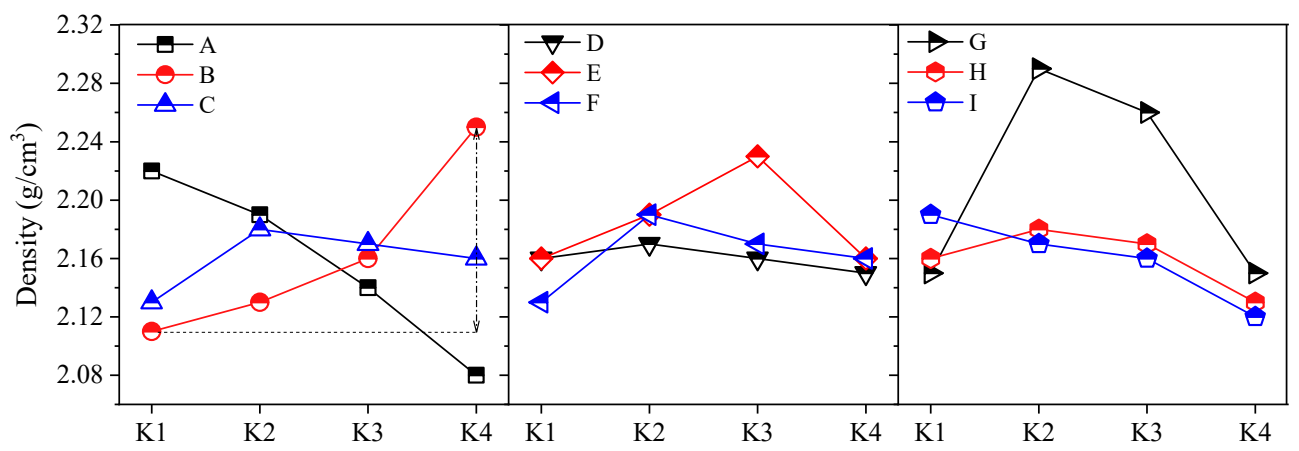

Figure 11. Influence of different factors on density of PAM.

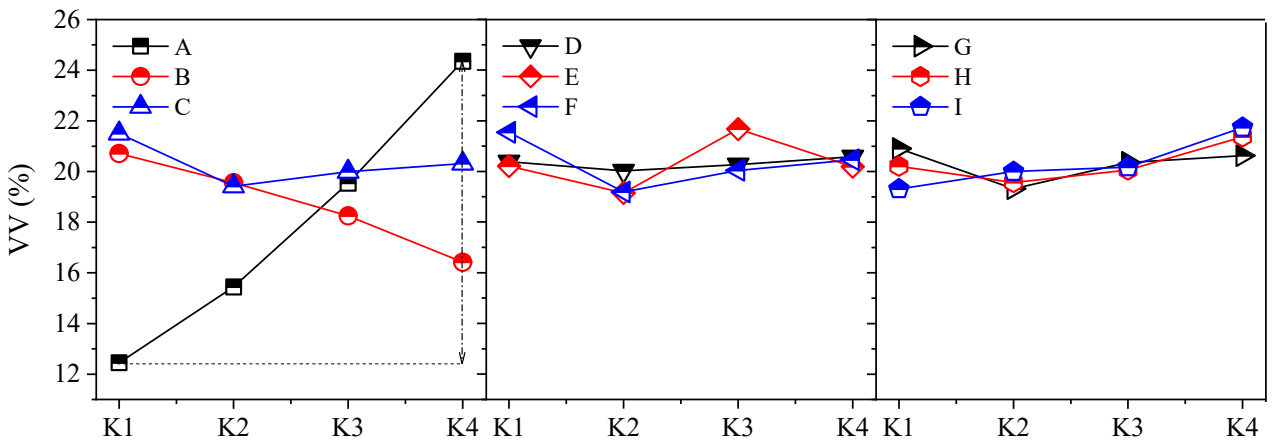

Figure 12. Influence of different factors on VV of PAM. 


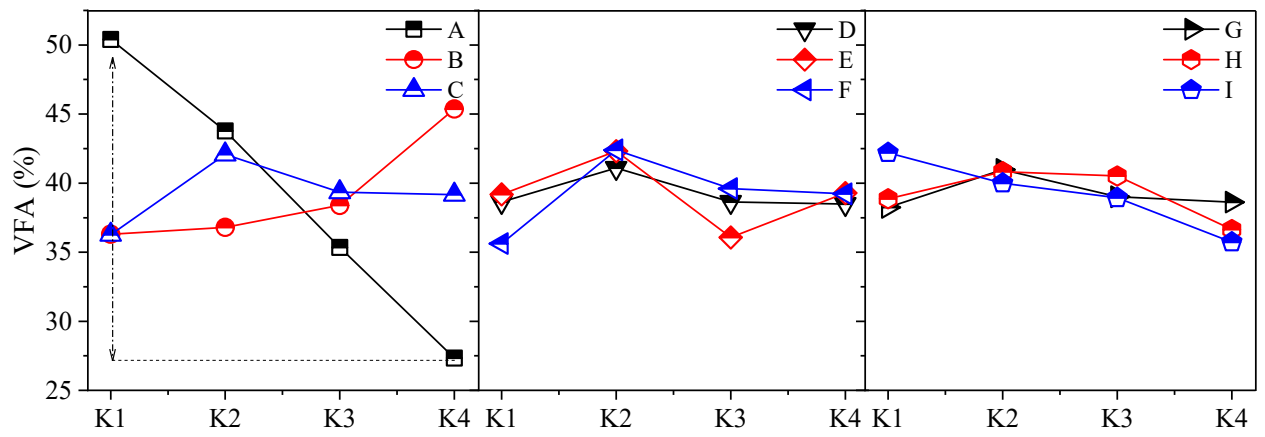

Figure 13. Influence of different factors on VFA of PAM.

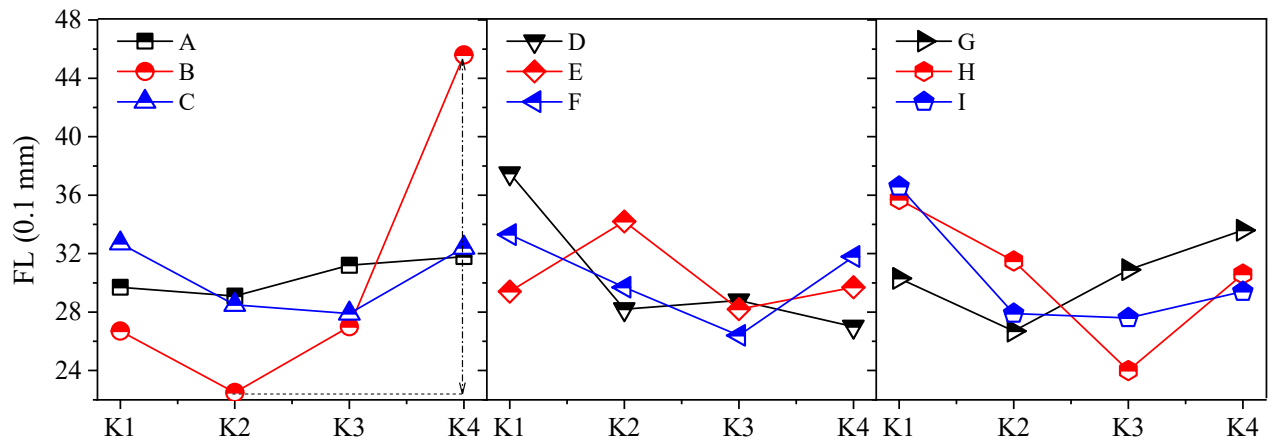

Figure 14. Influence of different factors on FV of PAM.

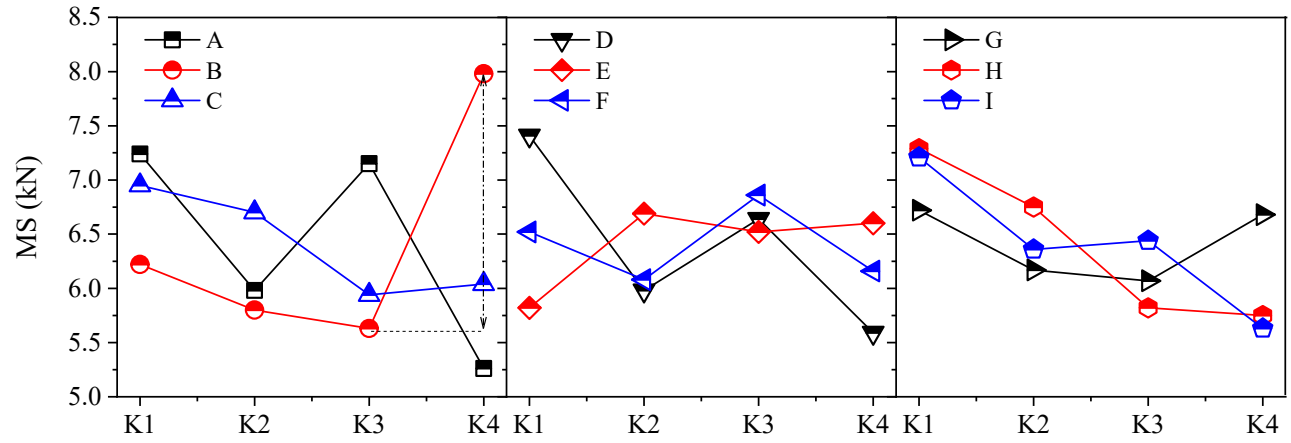

Figure 15. Influence of different factors on MS of PAM.

Table 10 shows the variance analysis results of the orthogonal test. The influence degree of different factors on mixture performance can be quantified, where * indicates the influence degree of investigation factors on performance. It can be seen from Table 10 that factors such as crumb rubber content, asphalt aggregate ratio, mixing temperature, compaction times, and forming temperature have a significant impact on the performance of the PAM, which should be paid attention to in the process of preparation parameter optimization. The factors that have a substantial impact on the density are crumb rubber content, asphalt aggregate ratio, and molding temperature; the factors that have a significant effect on the VV are asphalt aggregate ratio and crumb rubber content; and the most important factors on the VFA are asphalt aggregate ratio and crumb rubber content. Mixing time after adding asphalt and molding temperature also have an impact on the saturation. The significant factors affecting the FV are the crumb rubber content, compaction times, mixing temperature, and molding temperature. The significant factors affecting MS are crumb rubber content, asphalt aggregate ratio, mixing temperature, compaction times, and forming temperature. 
Table 10. Significance analysis of different factors on asphalt performance.

\begin{tabular}{|c|c|c|c|c|c|c|c|c|c|c|}
\hline \multirow{2}{*}{\multicolumn{2}{|c|}{$\begin{array}{c}\text { Performance of } \\
\text { PAM }\end{array}$}} & \multicolumn{9}{|c|}{ Influence Factors } \\
\hline & & \multirow{2}{*}{$\begin{array}{c}\mathbf{A} \\
17.33\end{array}$} & \multirow{2}{*}{$\begin{array}{c}\text { B } \\
18.56\end{array}$} & \multirow{2}{*}{$\begin{array}{c}\text { C } \\
2.27\end{array}$} & \multirow{2}{*}{$\begin{array}{c}\mathbf{D} \\
0.21\end{array}$} & \multirow{2}{*}{$\begin{array}{c}\mathrm{E} \\
2.72\end{array}$} & \multirow{2}{*}{$\frac{F}{2.68}$} & \multirow{2}{*}{$\begin{array}{c}\mathrm{G} \\
1.44\end{array}$} & \multirow{2}{*}{\begin{tabular}{c|}
$\mathbf{H}$ \\
1.65
\end{tabular}} & \multirow{2}{*}{\begin{tabular}{|c|}
$\mathbf{I}$ \\
3.09
\end{tabular}} \\
\hline Dencity & F value & & & & & & & & & \\
\hline Density & Significance & $* * *$ & $* * *$ & - & - & - & - & - & - & $*$ \\
\hline \multirow{2}{*}{ VV } & F value & 26.13 & 6.00 & 1.97 & 0.14 & 2.76 & 2.44 & 1.23 & 1.49 & 2.68 \\
\hline & Significance & $* * *$ & $* *$ & - & - & - & - & - & - & - \\
\hline \multirow[b]{2}{*}{ VFA } & F value & 42.67 & 7.46 & 2.38 & 0.67 & 2.76 & 3.27 & 0.63 & 1.56 & 3.07 \\
\hline & Significance & $* * *$ & $* * *$ & - & - & - & $*$ & - & - & $*$ \\
\hline \multirow{2}{*}{ FL } & F value & 0.43 & 26.11 & 1.61 & 5.57 & 1.57 & 2.18 & 2.04 & 5.64 & 4.16 \\
\hline & Significance & - & $* * *$ & - & $* *$ & - & - & - & $* *$ & $* *$ \\
\hline \multirow{2}{*}{ MS } & F value & 7.61 & 9.59 & 2.05 & 5.26 & 1.31 & 1.06 & 0.94 & 4.61 & 3.39 \\
\hline & Significance & $* * *$ & $* * *$ & - & $* *$ & - & - & - & $* *$ & * \\
\hline
\end{tabular}

Note: $\mathrm{F}$ value $\geq \mathrm{F}_{0.01}(3,9)=6.99:{ }^{* * *}, \mathrm{~F}$ value $\geq \mathrm{F}_{0.05}(3,9)=3.86:{ }^{* *}, \mathrm{~F}$ value $\geq \mathrm{F}_{0.10}(3,9)=2.91:^{*}$.

\subsubsection{Determination of Optimal Preparation Parameters}

It can be seen from Table 10 that among the selected factors and their investigation levels, the aggregate heating temperature, feeding sequence, and mixing time after adding crumb rubber have no significant impact on the properties of the mixture, and the mixing time after adding asphalt only has a substantial impact on the VFA. Therefore, based on the results of range analysis, technical parameters such as factors C, E, F, and G are preliminarily recommended. When selecting the best level of preparation parameters, parameters such as asphalt aggregate ratio, crumb rubber content, mixing temperature, compaction times, and forming temperature should mainly be investigated. According to Figures 11-15, it is preliminarily recommended that the aggregate heating temperature be $185^{\circ} \mathrm{C}$, and the feeding sequence of raw materials be level 2: mixing for $70 \mathrm{~s}$ after adding asphalt and $30 \mathrm{~s}$ after adding crumb rubber. During the actual preparation of the mixture, the above technical parameters can be determined in detail from the perspective of saving energy and improving construction convenience. Considering that the particle size and crumb rubber content have been determined in Section 3.3, the recommended crumb rubber content is $4 \%$. According to the variation of the basic properties of the PAM, the asphalt aggregate ratio is preliminarily recommended to be $5.5 \%$. The final asphalt aggregate ratio needs to be determined in combination with the dispersion test and leakage test. When the mixing temperature is $180^{\circ} \mathrm{C}$, the $\mathrm{FV}$ and $\mathrm{MS}$ of the mixture are the largest, and the values of other indicators are small. When the mixing temperature is $170^{\circ} \mathrm{C}$, the VV and density of the PAM are the largest, which indicates that the performance of the PAM mixed at this temperature is the best. In addition, the bonding performance among crumb rubber particles and asphalt is greatly affected by mixing temperature. When the temperature is $180{ }^{\circ} \mathrm{C}$, the surface of rubber particles is prone to carbonization and the bonding effect among asphalt and rubber particles is restrained. Therefore, the recommended mixing temperature is $170^{\circ} \mathrm{C}$.

When the compaction times is 70, the VFA, VV, and density of PAM with crumb rubber reach the maximum, and the FV and MS are relatively small. When the compaction times is 80 , the FV and MS of the mixture reach the maximum. It can be seen that the compaction times has a significant impact on the FV and MS of the mixture, and the recommended compaction times is 80 . When the molding temperature is $170^{\circ} \mathrm{C}$, all of the density, $\mathrm{VV}$, VFA, FV, and MS of PAM specimens reach the maximum. Therefore, it is recommended that the molding temperature of PAM be controlled at about $170^{\circ} \mathrm{C}$. In conclusion, according to the orthogonal test results, the best combination of preparation process of PAM with crumb rubber is determined to be $\mathrm{C}_{2} \mathrm{D}_{2} \mathrm{E}_{2} \mathrm{~F}_{2} \mathrm{G}_{3} \mathrm{H}_{1} \mathrm{I}_{1}$.

PAMs with crumb rubber were prepared according to the finally determined process parameters, and the influence of crumb rubber content on dispersion loss and leakage loss was further investigated. The mixing amounts of crumb rubber were $1 \%, 2 \%, 3 \%$, and $4 \%$ and the primary asphalt aggregate ratios were $4.5 \%, 5.0 \%, 5.5 \%, 6.0 \%$, and $6.5 \%$. 
Marshall tests, dispersion tests, and leakage tests were carried out; the results are shown in Table 11. By analyzing the test results, it can be concluded that with the increase of crumb rubber content, the optimal asphalt aggregate ratio of PAMs with crumb rubber gradually increases, and its FV and MS decrease. Therefore, the addition of crumb rubber not only enhances the damping performance of the mixture, but also affects its road performance. In engineering applications, it is necessary to consider the damping performance and road performance of the PAM at the same time to recommend a reasonable amount of crumb rubber.

Table 11. Test results of Marshall test, Cantabro test, and Sherenberg leakage test.

\begin{tabular}{ccccccc}
\hline \multirow{2}{*}{$\begin{array}{c}\text { Crumb } \\
\text { Rubber }\end{array}$} & $\begin{array}{c}\text { Optimal Asphalt } \\
\text { Aggregate }\end{array}$ & \multicolumn{5}{c}{ Evaluation Indexes } \\
\cline { 3 - 7 } & $\begin{array}{c}\text { VFA } \\
\text { Ratio (\%) }\end{array}$ & $\begin{array}{c}\text { MS } \\
(\mathbf{( \% )}\end{array}$ & $\begin{array}{c}\text { FV } \\
(\mathbf{k N})\end{array}$ & $\begin{array}{c}\text { Dispersion } \\
\mathbf{( 0 . 1} \mathbf{~ m m})\end{array}$ & $\begin{array}{c}\text { Leakage } \\
\text { Loss (\%) }\end{array}$ & Loss (\%) \\
\hline 1 & 5.3 & 19.55 & 5.45 & 25.5 & 12.3 & 0.062 \\
2 & 5.5 & 19.96 & 5.22 & 24.4 & 10.4 & 0.116 \\
3 & 5.6 & 20.25 & 4.85 & 23.6 & 8.6 & 0.154 \\
4 & 5.8 & 20.74 & 4.14 & 23.2 & 7.5 & 0.182 \\
\hline
\end{tabular}

\section{Conclusions}

The preparation process of high-viscosity modified asphalt for PAM containing crumb rubber was optimized in this study and the stability of different gradation types of PAM was compared. The range and optimal particle size of crumb rubber instead of aggregate were determined, the effects of different process parameters on mixture performance were evaluated, and the optimal preparation parameters of PAM were recommended. This study can be a reference for promoting the utilization of waste rubber in PAP and improving the noise reduction performance and durability of PAP. The main conclusions are as follows:

1. The increase of mixing time is not conducive to the low-temperature performance of high-viscosity modified asphalt. The toughness and adhesion of high-viscosity modified asphalt are improved after TFOT. It is recommended that the preparation process of high-viscosity modified asphalt be high-speed shearing for $1 \mathrm{~h}$, mechanical stirring for $2 \mathrm{~h}$, and a preparation temperature controlled between 185-190 ${ }^{\circ} \mathrm{C}$. According to the variation law of average unbalance force and average contact force, the recommended mixture grading is Gradation 2.

2. With the increase of crumb rubber content, the damping ratio of the mixing aggregate increases gradually. The increase of particle content and the size of crumb rubber leads to the decrease of the dynamic shear modulus of mixing aggregate. The addition of crumb rubber is conducive to significantly improving the damping performance and the toughness of the PAM, but it has an adverse impact on the bearing capacity.

3. Under low strain conditions, the damping ratio of the mixture with $2-5 \mathrm{~mm}$ crumb rubber is $1.2-5$ times that of the mixture with $0.6-1 \mathrm{~mm}$ crumb rubber. The selection of rubber particle size is consistent with the main particle size in aggregate gradation, which is conducive to giving play to its damping performance. The recommended optimum content of crumb rubber in the gradation of PAM is $4 \%$, and the optimum particle size of alternative aggregate is $2.36-4.75 \mathrm{~mm}$.

4. The factors that have a significant influence on the VV are the asphalt aggregate ratio and the crumb rubber content. The significant effects on the FV are the crumb rubber content, compaction times, mixing temperature, and molding temperature. The significant effects on MS are crumb rubber content, asphalt aggregate ratio, mixing temperature, compaction times, and forming temperature.

5. The recommended preparation parameters of PAM containing crumb rubber are as follows. The heating temperature of aggregate is $185^{\circ} \mathrm{C}$. The order of placing raw materials is aggregate, crumb rubber, asphalt, and mineral powder. The mixing times after adding asphalt and crumb rubber are $70 \mathrm{~s}$ and $30 \mathrm{~s}$, respectively, the mixing 
temperature is $170{ }^{\circ} \mathrm{C}$, the compaction times is 80 , and the molding temperature is about $170{ }^{\circ} \mathrm{C}$.

6. The damping performance of PAM containing recycled crumb rubber was evaluated in this study. The introduction of crumb rubber is conducive to vibration and noise reduction of porous asphalt mixture. However, the evolution of damping performance of PAM under the influence of environmental factors still needs to be further analyzed in future studies.

Author Contributions: Conceptualization, E.Q. and H.X.; investigation, E.Q. and Z.S.; writingoriginal draft preparation, E.Q. and Z.S.; writing—review and editing, H.X.; visualization, E.Q. and Z.S.; formal analysis, E.Q. and H.X.; supervision, H.X.; funding acquisition, H.X. All authors have read and agreed to the published version of the manuscript.

Funding: This research was funded by The National Natural Science Foundation of China (61203374).

Institutional Review Board Statement: Not applicable.

Informed Consent Statement: Not applicable.

Data Availability Statement: All data used in this research can be provided upon request.

Conflicts of Interest: The authors declare no conflict of interest.

\section{References}

1. Jiang, W.; Huang, Y.; Sha, A.M. A review of eco-friendly functional road materials. Constr. Build. Mater. 2018, 191, 1082-1092. [CrossRef]

2. Wen, P.H.; Wang, C.H.; Song, L.; Niu, L.L.; Chen, H.Y. Durability and sustainability of cement-stabilized materials based on utilization of waste materials: A literature review. Sustainability 2021, 13, 11610. [CrossRef]

3. Faruk, A.N.M.; Liu, W.T.; Lee, S.I.; Naik, B.; Chen, D.H.; Walubita, L.F. Traffic volume and load data measurement using a portable weigh in motion system: A case study. Int. J. Pavement Res. Technol. 2016, 9, 202-213. [CrossRef]

4. Fassbender, S.; Oeser, M. Investigation on an absorbing layer suitable for a noise-reducing two-layer pavement. Materials 2020, 13, 1235. [CrossRef]

5. Martin, W.D.; Putman, B.J.; Neptune, A.I. Influence of aggregate gradation on clogging characteristics of porous asphalt mixtures. J. Mater. Civ. Eng. 2014, 26, 04014026. [CrossRef]

6. $\quad$ Li, H.Z.; Xu, H.N.; Chen, F.C.; Liu, K.D.; Tan, Y.Q.; Leng, B.B. Evolution of water migration in porous asphalt due to clogging. J. Clean. Prod. 2022, 330, 129823. [CrossRef]

7. Ma, H.X.; Yu, H.F.; Tan, Y.S.; Da, B. Ice pressure and icing volume expansion rate of acetate-based deicers under freezing conditions. Constr. Build. Mater. 2021, 305, 124751. [CrossRef]

8. Wang, C.H.; Cao, H.Y.; Wang, S.; Gao, Z.W. Design and testing of road piezoelectric power generation device based on traffic environment applicability. Appl. Energy 2021, 299, 117344. [CrossRef]

9. Tahami, A.; Gholiakhani, M.; Dessouky, S.; Montoya, A.; Walubita, L.F. Evaluation of a roadway thermoelectric energy harvester through fe analysis and laboratory tests. Int. J. Sustain. Eng. 2021, 14, 1016-1032. [CrossRef]

10. Walubita, L.F.; Djebou, D.C.S.; Faruk, A.M.; Lee, S.I.; Dessouky, S.; Hu, X.D. Prospective of societal and environmental benefits of piezoelectric technology in road energy harvesting. Sustainability 2018, 10, 383. [CrossRef]

11. Gholikhani, M.; Sharzehee, M.; Tahami, S.A.; Martinez, F.; Dessouky, S.; Walubita, L.F. Effect of electromagnetic energy harvesting technology on safety and low power generation in sustainable transportation: A feasibility study. Int. J. Sustain. Eng. 2019, 13, 373-386. [CrossRef]

12. Anting, N.; Din, M.F.M.; Iwao, K.; Ponraj, M.; Jungan, K.; Yong, L.Y.; Siang, A.J.L.M. Experimental evaluation of thermal performance of cool pavement material using waste tiles in tropical climate. Energy Build. 2017, 142, 211-219. [CrossRef]

13. Chen, M.; Chu, J.W. $\mathrm{NO}_{x}$ photocatalytic degradation on active concrete road surface-From experiment to real-scale application. J. Clean. Prod. 2011, 19, 1266-1272. [CrossRef]

14. Wang, C.H.; Wang, S.; Gao, Z.W.; Song, Z. Effect evaluation of road piezoelectric micro-energy collection-storage system based on laboratory and on-site tests. Appl. Energy 2021, 287, 116581. [CrossRef]

15. Wang, C.H.; Chen, Q.; Guo, T.T.; Li, Q. Environmental effects and enhancement mechanism of graphene/tourmaline composites. J. Clean. Prod. 2020, 262, 121313. [CrossRef]

16. Hu, J.Y.; Ma, T.; Zhu, Y.H.; Huang, X.M.; Xu, J.; Chen, L.B. High-viscosity modified asphalt mixtures for double-layer porous asphalt pavement: Design optimization and evaluation metrics. Constr. Build. Mater. 2021, 271, 121893. [CrossRef]

17. Lyons, K.R.; Putman, B.J. Laboratory evaluation of stabilizing methods for porous asphalt mixtures. Constr. Build. Mater. 2013, 49, 772-780. [CrossRef] 
18. Putman, B.J.; Lyons, K.R. Laboratory evaluation of long-term draindown of porous asphalt mixtures. J. Mater. Civ. Eng. 2015, 27, 04015009. [CrossRef]

19. Wang, X.W.; Gu, X.Y.; Ni, F.J.; Deng, H.Y.; Dong, Q. Rutting resistance of porous asphalt mixture under coupled conditions of high temperature and rainfall. Constr. Build. Mater. 2018, 174, 293-301. [CrossRef]

20. Ferrari, A.; Kubilay, A.; Derome, D.; Carmeliet, J. The use of permeable and reflective pavements as a potential strategy for urban heat island mitigation. Urban Clim. 2020, 31, 100534. [CrossRef]

21. Yu, T.J.; Zhang, H.T.; Wang, N.; Wang, H.M.; Chen, D. Multi-scale analysis of sustainable service performance for porous asphalt pavement in Sponge City under freeze-thaw environment. Urban Water J. 2022, 19, 173-182. [CrossRef]

22. Yang, G.L.; Wang, C.H.; Wen, P.H.; Yin, W.Y. Performance characteristics of cold-mixed porous friction course with compositemodified emulsified asphalt. J. Mater. Civ. Eng. 2020, 32. [CrossRef]

23. Li, H.Y.; Li, Z.F.; Zhang, X.R.; Li, Z.R.; Liu, D.Q.; Li, T.H.; Zhang, Z.Y. The effect of different surface materials on runoff quality in permeable pavement systems. Environ. Sci. Pollut. Res. 2017, 24, 21103-21110. [CrossRef]

24. Akhtar, M.N.; Al-Shamrani, A.M.; Jameel, M.; Khan, N.A.; Ibrahim, Z.; Akhtar, J.N. Stability and permeability characteristics of porous asphalt pavement: An experimental case study. Case Stud. Constr. Mater. 2021, 15, e00591. [CrossRef]

25. Li, X.L.; Shen, J.N.; Ling, T.Q.; Yuan, F.G. Fatigue properties of aged porous asphalt mixtures with an epoxy asphalt binder. J. Mater. Civ. Eng. 2022, 34, 04021488. [CrossRef]

26. Kong, P.P.; Xu, G.; Chen, X.H.; Shi, X.D.; Zhou, J. Effect of different high viscosity modifiers on rheological properties of high viscosity asphalt. Front. Struct. Civ. Eng. 2021, 15, 1390-1399. [CrossRef]

27. Kassem, E.; Walubita, L.; Scullion, T.; Masad, E.; Wimsatt, A. Evaluation of full-depth asphalt pavement construction using X-ray computed tomography and ground penetrating radar. J. Perform. Constr. Fac. 2008, 22, 408-416. [CrossRef]

28. Sun, J.F.; Zhang, H.T.; Yu, T.J.; Liu, Z.Q. Meso simulation and macro experimental study of noise reduction in porous asphalt mixtures. J. For. Eng. 2021, 6, 165-171.

29. Zhu, J.Q.; Ma, T.; Lin, Z.H.; Xu, J.; Qiu, X.H. Evaluation of internal pore structure of porous asphalt concrete based on laboratory testing and discrete-element modeling. Constr. Build. Mater. 2021, 273, 121754. [CrossRef]

30. Jiang, W.; Yuan, D.D.; Shan, J.H.; Ye, W.L.; Lu, H.H.; Sha, A.M. Experimental study of the performance of porous ultra-thin asphalt overlay. Int. J. Pavement Eng. 2020. [CrossRef]

31. Wang, X.W.; Hu, X.Y.; Gu, X.Y.; Li, Q.; Li, W.X.; Chen, B. Microstructure and damage evolution of porous asphalt mixtures under coupled effects of high temperature and moisture. Int. J. Pavement Eng. 2021. [CrossRef]

32. Chai, C.; Cheng, Y.C.; Zhang, Y.W.; Zhu, B.; Liu, H. Mechanical properties of crumb rubber and basalt fiber composite modified porous asphalt concrete with steel slag as aggregate. Polymers 2020, 12, 2552. [CrossRef] [PubMed]

33. Cui, X.Z. Dynamic numerical analysis of antimoisture-damage mechanism of permeable pavement base. Int. J. Geomech. 2010, 10, 230-235. [CrossRef]

34. Li, Q.; Qiao, F.X.; Yu, L. Impacts of pavement types on in-vehicle noise and human health. J. Air Waste Manag. Assoc. 2016, 66, 87-96. [CrossRef]

35. Li, M.L.; van Keulen, W.; Ceylan, H.; van de Ven, M.; Molenaar, A. Influence of changes in surface layer properties on tire/pavement noise. Noise Control Eng. J. 2013, 61, 417-424. [CrossRef]

36. Costello, J.M.; Steurer, M.A.; Baer, R.J.; Witte, J.S.; Jelliffe-Pawlowski, L.L. Residential particulate matter, proximity to major roads, traffic density and traffic volume as risk factors for preterm birth in California. Paediatr. Perinat. Epidemiol. 2022, 36, 70-79. [CrossRef]

37. Mohammadi, S.; Ohadi, A. A novel approach to design quiet tires, based on multi-objective minimization of generated noise Appl. Acoust. 2021, 175, 107825. [CrossRef]

38. Xiao, F.P.; Wang, T.; Wang, J.Y.; Su, N.Y.; Hou, X.D.; Chen, J.; Liu, J. Mechanism and research development of noise reduction technology of rubberized asphalt pavement. China J. Highw. Transp. 2019, 32, 73-91.

39. Alber, S.; Ressel, W.; Liu, P.; Hu, J.; Wang, D.; Oeser, M.; Uribe, D.; Steeb, H. Investigation of microstructure characteristics of porous asphalt with relevance to acoustic pavement performance. Int. J. Transp. Sci. Technol. 2018, 7, 199-207. [CrossRef]

40. Wang, H.; Dong, X.Y.; Deng, Q.; Shi, L. Sound absorption performance of asphalt mixture. J. Build. Mater. 2018, 21, 634-638. [CrossRef]

41. Ren, S.S.; Liu, X.Y.; Xu, J.; Lin, P. Investigating the role of swelling-degradation degree of crumb rubber on CR/SBS modified porous asphalt binder and mixture. Constr. Build. Mater. 2021, 300, 124048. [CrossRef]

42. Jiao, Y.B.; Liu, S.Q.; Fu, L.X.; Shan, W.C. Fracture monitoring of sbs and crumb rubber modified porous asphalt mixtures under compression and splitting testing using acoustic emission technique. J. Mater. Civ. Eng. 2019, 31, 04019063. [CrossRef]

43. Franesqui, M.A.; Yepes, J.; Garcia-Gonzalez, C. Improvement of moisture damage resistance and permanent deformation performance of asphalt mixtures with marginal porous volcanic aggregates using crumb rubber modified bitumen. Constr. Build. Mater. 2019, 201, 328-339. [CrossRef]

44. JTGE 20-2011; Standard Test Methods of Bitumen and Bituminous Mixtures for Highway Engineering. China Communications Press Co., Ltd.: Beijing, China, 2011.

45. JTGD 50-2017; Specifications for Design of Highway Asphalt Pavement. China Communications Press Co., Ltd.: Beijing, China, 2017.

46. CJJ/T 190-2012; Technical Specification for Permeable Asphalt Pavement. China Architecture \& Building Press: Beijing, China, 2012. 
47. JTG/T 3350-03-2020; Technical Specifications for Design and Construction of Porous Asphalt Pavement. China Communications Press Co., Ltd.: Beijing, China, 2020.

48. Li, J.S.; Zhu, Z.; Ke, L.; Wang, Z.Y. Rheological performance investigation of high viscosity liquid asphalt. Road Mater. Pavement 2021, 22, 2674-2688. [CrossRef] 